\title{
Causes and Preventions of Fires in Balloons ${ }^{*}$
}

\author{
Conclusions Based on Investigations of Fires at Various Army Camps
}

By Dr. W. F. Swann

During deflation of a Caquot balloon at Fort Sill, the balloon continued to veer where the men had got hold of the manœuvring lines, and almost struck the ground a number of times. Toggles began to be ripped out of the rigging band, and it became evident that the only chance of saving the balloon was to rip the panel.

The ripping panel was ripped and the valve taken out. It was stated that "there appeared to be no gas in the nose of the balloon." When about onethird of the gas had left the envelope there was an explosion, and a blinding flare of flames. The balloon rose about 10 peet in the air all in flames; the cable prevented its rising higher. It then settled to the ground and burned.

Because men handled sand bags, enabling the baloon to be held to the ground, twenty-four me on the leeward side of the balloon were burned One of the reports says:

After being rinped, about two-thirds of the gas had
escaped, when a streak of fire was noticed coming from the top ef the ball streak of fire was nothed coming from the top of the balloon traveling down across the ripping pane
holes. At this instant the whole balloon burst into flames. Another report reads:

The balloon was blowing from side to side as it was bein hauled down, and when it got near to the ground, it dive
over, and the nose struck the ground. The balloon appeared over, and the nose struck the ground. The balloon appeared
to be losing gas as the nose was caving in. Five holes were to be losing gas as the nose was caving in. Five holes were
observed on one side of the ballon. A flash of fire appeared at the nose of the balloon. and spread almost stantaneously over the balloon.

A photographer happened to be on hand at the time, and his report describes the forward third of the balloon as being the part which first burst into flames, the flame being instantly driven back by the flames, the flame being instantly driven
wind so as to envelop the entire bag.

The balloon had apparently lost a great deal of gas, and an amply sufficient explanation of th formation of an explosive mixture in the balloo is io be found in the removal of the valve, thus forming an opening at a place other than at the highest point. The fact that the valve was removed when the ripping panel was open enormously aggravated the circumstance, resulting in an outflow of hydrogen at the ripping panel, and an inflow of air at the gen at the ripping panel, and an inflow of air at the
valve. The small holes which had been torn in the valve. The small holes which had been torn in the
side of the balloon possibly contributed in some slight degree to the effect; but their influence would probably be small compared with that caused by removing the valve.

Two of the reports implied a flabby condition at the nose of the balloon, indicating that the pressure outside the balloon at the point was greater than the pressure inside. One report speaks of a "flash of fle occurring at the nose of the balloon," and of flre occurring at the nose of the balloon," and
the photographer's report speaks of the forward one-third of the balloon as being the first part to burst into flames. Both of these accounts are in harmony with the conclusion that the forward part of the balloon was the seat of the explosive mixof the

The first of the above abstracted reports speak of a "streak of fire coming from the top of th baloon, traveling down the ripping panel holes." The current of gas established between the rippin panel and the valve opening by the entrance of air at the latter and the exit of hydrogen through the iormer would result in an explosive mixture at along this path, so that a flame started at one place would propagate itself almost immediately over thi region, and it would be difficult to say from the general appearance just which way the explosion general app

There was a high wind, and as there is a great deal of dust at Fort Sill the conditions were just such as to be favorable to the electrification of the balloon by the dust blowing upon it. This conclusion is supported by the statement in one of the reports. to the effect that a spark of considerable intensity was obtained from the winch, and by the reports of the Radio Offcer, who spoke of the elecreports of the Radio Offlcer, who spoke of the elec-
tro-statir, conditions prevailing on this day. I would tro-statir conditions prevailing o
call attention to the following:

In order for the snark to have resulted in exnlosion it was necessarv for it to have occurred at a place where there was
an exnlosire mixture. There would he an explosive mixture an exnlosire mixture. There would he an explosive mixture
at the rin-nanel where gas was discharging into the afr. and there would he an exnlnsive mixtnre at the annendix ally made: for. In splte of what has already heen sald with

- From $\bar{C}$. \&. Air service.

\section{TO OUR SUBSCRIBERS}

We are still laboring under the tremendous handicap imposed upon us by the strike of pressmen and compositors and again we are obliged to publish a double number of the SCIENTIFIC A MERIcan Supplement this time combining the issues of November Ist and Sth. We hope however to resume our weekly schedule with the issue of November 15th, which however acill probably be somewhat delayed. We wish to thank you for your indulgence in ihese distressing conditions.

regard to the inflow of air at these lower openings there
would be periods when gas was forced out of them as a would be periods when gas was forced out of them as a
result of the rolling and general agitation to which the result of the rolling and general agitation to which the
balloon was subjected. Again, the irregular nature of the balloon was subjected. Again, the irregular nature of the
gusts of wind might well result in enough hydrogen being from time to time blown down to cause an explosive mixture at any point where the men were working, especially
when we remember that 5 per cent. of hydrogen will render when we remember that
the mixture explosive.

The spark certainly did not occur during the ripping of
the panel, for it was a considerable time after this that the explosion occurred. It is not $11 \mathrm{kely}$ that it occurred at the rip panel at all; for in spite of the strong electrification to which the balloon was probably subjected, there was no
opportunity for a spark to pass hetween two conductors or between a conductor and the fabric in this region, since no conductors were present there. At the ground level there was. however. plenty of oppor-
tunnity for sparking, as for example between two men who had become charged to different extents by the particles of dust in the air, by friction resulting from rubbing against the balloon, or by discharge of a portion of the balloon'
surface by direct contact with it. Again a spark may have surface by direct contact with it. Again a spark may have
occurred between one of the men and the charge balloon occurred between one of the men and the charge balloon
fabric, or one of the conductors, metal hooks or ropes assofabric, or one of the conductors, metal hooks or ropes asso-
ciated with the sand bags. If it so hapnened that any part ciated with the sand bags. If it so happened that any part
of the valve attachment was not removed from the valve of the valve attachment was not removed from the valve
onening there would have been a gond opportunity for a
spark to pass between this part and any one who touched it. Thus the conditions were such that there was ample opportunity for the presence of small quantities of explosive mixture and of sparking of various places outside the balloon. The Ignition of the mixture at a point in the vicinity of one of the openings would result in the propagation of the flame into the balloon in view of the existence of an explosive mixture there. The main explosion would of course result from this latter mixture in view of its having collected in large quantities. The explosion would rip open the fore part of the balloon and thus expose the remainder of the hydrogen. which would become ignited and burn until it has been consumed. with a speed rather slow compared with the explosion.

The writer is thus of the opinion that the pri mary cause of the major explosion which destroyed inside as a result of there being an opening at the valve while gas was discharging from the rip-panel The conditions were favorable to the formation electric sparks, and the writer is of the opinion that such a spark was formed in a small quantity of explosive mixture on the outside of the balloon nea one of the openings, with the result that the explosive flame was propagated through the opening to the main body of the explosive mixture inside.

Another case is that of a free balloor of 9000 cubic foot capacity, leaving Fort Omaha at 8:30 A.M. on June 15, 1917. The weather was calm and the balloon traveled only 9 miles in one iour. At 10:40 A.M. the pilot made a landing. He then ascended to an altitude of 6000 feet and again landed near miles per hour.

The landing was made without ripping the panel. and the pilot got out of the basket, pulled down the net so as to reach the valve, and unhooked the valve spring so as to facilitate the escape of the inydrogen. He then started to pull the net so as to get gen. He then started to pull the net 60 as to get the valve once more to the top. When the valve
was approximately at the desired position, he, to use his own words, "Heard the characteristic sound of ignited hydrogen," and, realizing the possibility of sudden explosion, threw himself down on the ground to protect his face. The explosion followed immediately; the envelope was gone in a few seconds.

I would impress upon the reader the following facts:

The region surrounding the place where hydrogen escapes into the air is always the seat of an explosive mixture. The "characteristic sound of ignited hydrogen" referred to by the pilot evidently corresponds to the "pop" or miniature
explosion resulting from the ignition of the explosive gas explosion resulting from the ignition of the explosive gas
at the valve opening. The valve being open, and the appenat the valve opening. The valve being open, and the appen-
dix being also open, the conditions were favorable for the formation of an explosive column of gas between the two openings.

So long as the initial velocity with which a flame would start be propagated through this explosive column (a velocity of the order of magnitude of one or two meters per
second was less than the velocity of efflux of the gas from second) was less than the velocity of efflux of the gas from
the valve, the explosion would be unable to propagate itself. or "strike back" into the balloon.

This would appear to be the condition prevalling at the instant when the ignition was first noticed. At this time hearing the initial miniature explosion he This would produce a sudden diminution of the pressure in the balloon and consequently a diminution of the velocity of efflux of gas, enabling the flame to strike back into the balloon and explode the whole of the explosive mixture contained therein. In this way the major explosion is accounted for as occurring an instant after the initial minor explosion.
a circumstance which seems to be implied in the pilot's re-

The major explosion probably represented the combustion of the explosive mixture in the column joining the two opencolumn. A quantity of hydrogen of a degree of purity
com comparable with that in the balloon at the moment of
descent would yet remain, and this would burn with a speed
relatively slow relatively slow compared with that of the explosion, a cir-
cumstance borne out by the pilot's statement that the cumstance borne out by the pilot's stat
envelope was consumed "in a few seconds."

The hydrogen used for a free balloon is usually taken from a kite balloon when the purity is insufficient to provide a satisfactory lifting power in the latter. Further, in descending, a pree balloon will to some extent take in air through the appendix, although the automatic construction of the latter by the increase of external pressure minimizes the influx of air. However, there is always a certain possibility that the gas in the free balloon is explosive. That such was not the case in the instance under discussion, however, is borne out by the fact that the gas burned for a few seconds after the major explosion, and we are thus lead to the conclusion that the primary cause of the explosion inside the balloon was to be found in the column of explosive gas which originated as a result of the appendix being open while the hydrogen was discharged from the valve.

The primary origin of the spark was probably the electrification of the surface of the balloon by the friction resulting from pulling the net over it. The spark might arise in several ways. It might occur between the fabric and the net rope; or, some part of the valve which was conducting but was insulated from other conducting parts might spark to one of these parts as a result of its having become charged by leakage from the charged envelope.

The first ignition of the escaping gas was caused by an electric spark which occurred in the vicinity of the valve and the major erplosion was caused by the striking back of the flame into the explosive column of air which resulted from the presence of column of air which resulted from the presence
two openings in the balloon, at different angles.

It was ou Cinristmas Day, 1917, that an explosinu occurred wbirh destroyed a Caquot balloon during deflation, immediately following partial inflation at Fort Sill. The weather was dry and cold and slight snow was falling. Tile balloon was a new Caquot, just received from the manufacturers. After it had been unpacked from its case, spread out on the floor of the hangar, inspected carefully, and attached to the hydrogen cylinder trucks, the gas was carefully turned on, and the inflation proceeded under the direction of experienced officers.

The first indication of trouble was a slight "pop" which occurred before the inflation reached the valve. No smoke resulted, and nothing more was thought of it.

Later, when about 15,000 cubic feet of gas were in (Concluded on page 280) 
Lac Cultivation in India.

The lac industry has for many years formed the means of livelihood of thousands of the poorer classes of India, especially those inhabiting the outskirts of the forests and other areas where the lac insect abounds.

Lac is a secretion produced by an insect which sucks the juice of plants and transforms it into resin. This secretion hardens on exposure to the air into a deep-red or orange-colored substance, semi-transparent, and breaking with a crystalline fracture. The insect belongs to a group commonly known as scale insects.

At the time of emergence the young insect is about $1 / 25$ of an inch in length and deep-red in color.

After sluggishly wandering about and finding a suitable spot, it fixes itself and then thrusts its beak suitable spot, it fixes itself and then thrusts its beak
into the tissues of the stem and begins sucking the juice. The sap thus taken into the body is greatly transformed, and is given out uniformly through pores all over the body in the form of resin, which after a few days encases the insect completely. Female insects remain fixed once for all, but male in sects emerge twice a year, sometimes as winged creatures.

The lac-bearing branches are cut off and placed on trees having a sufficient number of succulent branches. When the young insects have swarmed out, the old lac-bearing branches are removed and the resinous incrustation (stick-lac) is scraped off with a knife, ground in a mill, soaked in water, and washed. The pure animal resin (seed-lac) thus obtained is mixed with colophony and orpiment, cooked over a slow fire and drawn out into thin sheets, which form it is commercially known as shellac.

The United States Vice-Consul in Calcutta calls attention to some interesting details furnished by $\mathrm{Mr}$. C. S. Misra, first assistant to the Imperial Entomologist at the Agricultural Research Institute, Pusa, regarding the present condition of lac cultivation in th plains of India. During the last decade the industr has passed through many vicissitudes. Over-produc tion, no doubt, contributed to a large extent to the lowering of prices of the crude material. Prices lowering of prices of the crude material. Prices reached their lowest point about a year after the out break of the Great War-22 rupees per maund (about $£^{2}$ per wt.)-at which figure lac cultivation is hardly worth while. New uses were then found for shellac, and its exportation was limited, after which prices rose. With the steadying of prices or shellac the flow of the crude material has again become about normal. One result of the stimulus afforded by present high prices is that many person have started the cultivation of lac in localities where success is doubtful, because the climptic conditionsan important factor in the development and subsequent acclimatization of the lac insect-are decidedly unfavorable. On the other hand, few new r.tempt at lac cultivation have been made in localities which at precent meet practically three-fourths of the world demand.

India is the only country in the world, says $\mathrm{Mr}$ Misra, which supplies the market with shellac in it various manufactured forms. The Japanese have been trying to grow lac in Formosa, the German experimented with lac in Amani (German East A rica), and the Department of Agriculture in Egyp has also tried to introduce the industry there. The Indian Agricultural Research Institute furnished brood-lac for these three experiments, but definite in formation regarding their success or failure has no yet been received.

In the years when the prices rise, as was the case from 1905 to 1907 , and again during 1915 and 1916 attempts are made to oust the natural lac from the market with a synthetic product, but these attempt prove unsuccessful, as the constituents of the synthetic article either cannot be obtained in bulk o the cost of manufacturing it leaves too small a profit. However, it is reasonable to expect that the partialit at present shown by consumers for shellac, which even in its standard form is more or less adulterate with foreign ingredients, such as colophony and orp ment, will at some time give way to a preference for seed-lac, which is a pure animal product, and which impurities can be easily detected.

The Agricultural Research Institute at Pusa has ccnducted experiments in the treatment of pure la by grinding stick-lac to standard size, soaking an washing in water, adding monohydrated sodium carbonate, then aerating, and frequently turning in the shade until thoroughly dehydrated. Samples of the product, whith was a beautiful pale brown in color and considerably superior to the seed-lac obtaine without the addition of the alkali, were judged by a
London firm to be twice the value of the untreated oduct.

It is pointed out by Mr. Misra that the supply of stick-lac can be increased by removing all the lac from the trees a fortnight before the swarming of the young insects takes place and putting it on trees already pruned for the purpose, and then not gathering the stick-lac until after the swarming occurs, instead of before, as has often been done. Prior to 1908 , when lac dye was a marketable product of considerable importance, it paid to remove the stick-lac before swarming and when rich in coloring matter; but now, with the introduction and extensive use of aniline and other dyes, lac dye has sunk into insignificance. Experience has shown that stick-lac obtained from pruned trees is richer in resinous content than that obtained from unpruned trees, and that the successive broods reared on pruned trees are not so liable to disease. It is also a noteworthy fact that brood-lac should be obtained from a locality having similar climatic conditions to those obtaining in the place to which it is to be transported, and that brood-lac does best when transferred to a tree of the same species as the one from which it was taken. The heaviest lac production is in the northeastern section of the Indian Peninsula, in parts of the United Provinces, Central Provinces, and the Province of Bihar and Orissa. There is also an area in Eastern Burma, one in Western Sind, and a section of Central Assam, where quite large quantities of lac are collected, as well as smaller quantities in scattered sections.

The value of the shipments of lac (mostly shellac) from India in $1916-17$ was $£ 1,819,000,78$ per cent. gcing to the United States, which has been the largest buyer of Indian lac for the last twenty years.

The extent to which export values have risen is clearly seen in the 1916-17 trade figures; for, with a total value of $£ 704,000$ greater than in $1915-16$, the quantity of lac shipped from India was 35,971 cwt. less. Exports to the United Kingdom-India's second best customer-showed a decline of nearly 50 per cent. in quantity in 1916-17. Practically all the lac exported from India now goes out through the ports of Bengal, as the following table shows:

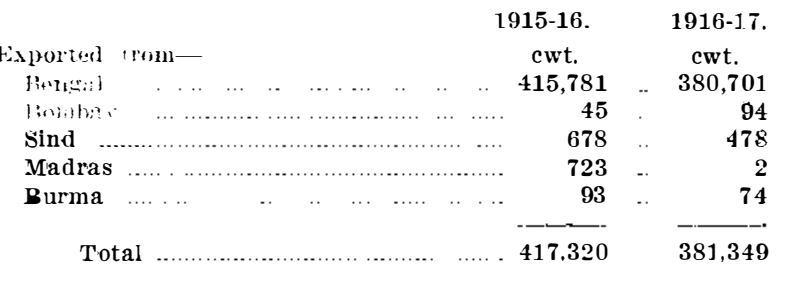

In 1917-18, India's shipments of lac of all kinds (excluding lac dye) reached the record value of $£ 2$, 451,000 , accompanied by a drop in quantity exported to $322,420 \mathrm{cwt}$. - (From the Journal of the Royal Society of Arts.

\section{Causes and Preventions of Fires and Balloons} (Continued from page 258.)

the balloon, a slightly louder "pop" was heard near the valve, which, by this time had been raised abou 3 feet from the floor. Bluish vapors arose from a small area a little above and behind the valve. Sergeant Hamilton gathered the valve and fabric in his arms. The vapor ceased and the fabric which had begun to blister cooled off. There were no visible flames on the outside, and the inner surface was later found to be only scorched.

A more violent explosion occurred almost immediately after, and smoke began coming from the surface of the balloon on the rear left side above th kallonet. The hydrogen was turned off, and the company left the hangar. However, the smoking soon ceased, so after a few minutes when the danger had apparently passed, the balloon was removed to a nearby field and moored down. It was found to be scorched on the right side near the valve, and on the rear left side of the ballonet.

Further experiments and inspection appeared to prove that the explosions which occurred in the hangar were produced as the result of explosive mixtures formed by the release of air contained in the pockets which had been formed as a result of the freezing together of the fabric. The electric sparks which caused the ignition appear to have been producd by the tearing apart of the frozen surface of the fabric

The larger amount of explosive mixture which formed in the balloon when outside the hangar resulted from an opening having been made at a place in the balloon other than at the top, while the balloon was only partially filled. The circumstance was further aggravated by there being two openings, the valve and the appendix. It is probable that the spark primarily responsible for this explosion resulted in the same way as those which occurred in the balloon when in the hangar.

\section{SCIENTIFIC AMERICAN SUPPLEMENT}

\section{Published by Scientific American Publishing Co}

New York, Saturday, October 25, 1919.

Munn \& Co., 233 Broadway, New York

Charles Allen Munn, President; Orson D. Munn, Treasure

Allan C. Hoff man, Secretary, all at 233 Broad way

The Scientific American Publications

Scientific American Supplement (established 1876) per year $\$ 5.00$. Scientific American (established 1845) $\quad 5.00$ The combined subscription rates and rates to foreign countrie
including Canada, will be furnished upon application. Remit by postal or express money order, bank draft or check.

Scientific American Publishing Co. 233 Broadway, New York

The purpose of the Supplement is to publish the more important announcements of distinguished technologists, to digest significant articles that appear in European publications, and altogether to reflect the most advanced thought in science and industry throughout the world.

Back Numbers of the Scientific American Supplement

Supplements bearing a date earlier than January 1st, 1918, can be supplied by the H. W. Wilson Company, 958-964 University Ave., Bronx, New York, N. Y. Please order such back numbers from the Wilson Company. Supplements for January 1st, 1918 , and subsequent issues can be supplied at 10 cents each by Scientific American Publishing Co., 233 Broadway, New York.

We wish to call attention to the fact that we are in a postion to render competent services in every
branch of patent or trade-mark work. Our staff is composed of mechanical, electrical and chemical experts, thoroughly trained to prepare and prosecute all patent applications, irrespective of the complex nature of the subject matter involved, or of the specialized, technical, or scientific knowledge required therefor.

We also have associates throughout the world, who assist in the prosecution of patent and trade-mark applications filed in all countries foreign to the United States.

Branch Office:

625 F Street, N. W., MUNN \& Co.,

Washington, D. C New York $N$. Y.

Table of Contents

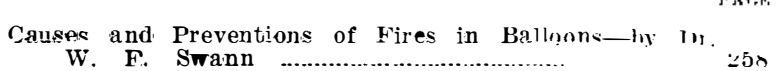

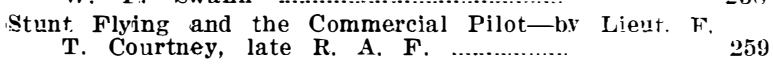

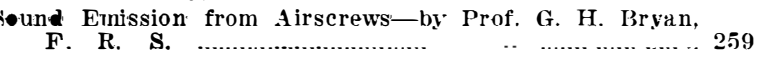
toms and Molecules-by Jean Becquerel, Prof. at the
Museum of Natural History in Paris: Illustrated 260 "Storms of Cold" and Their Paths ... ........................... 263

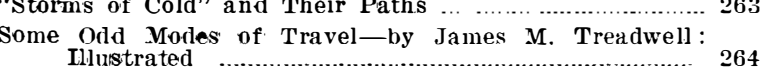

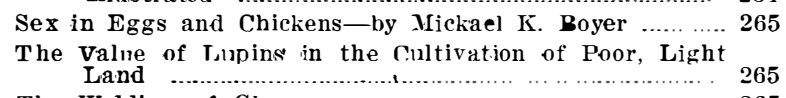

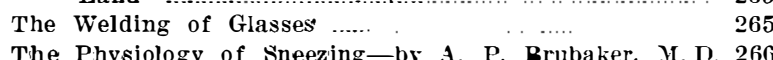
Monistic and Dualistic Conceptions of the Stellar Ini-
verse-II-(concluded)

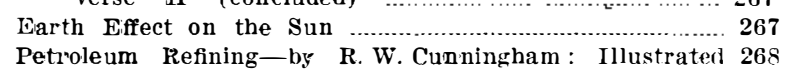
Petroleum Refining-by R. W. Cunningham : Illustrated 268
Electricity in Agriculture ................................ 269

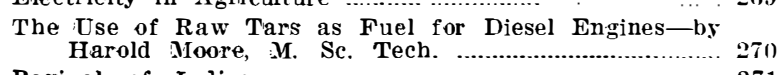
Revival of Tndigo

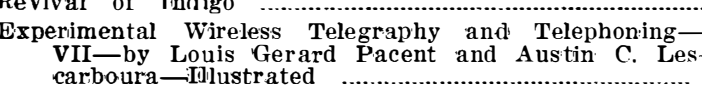
carboura - INlustrated -........................................ Ferments and Catalyzers-by Prof. Paul Sabatier........ 2274
Better Concrete-II-by Nathan C. Johnson-Ilustrat 270

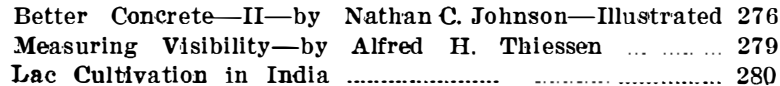

